\title{
Current capital optimization by the mathematical modelling of interconnections between its components
}

\author{
Valentina Orlova \\ Accountig and taxation dept. \\ Ivano-Frankivsk National Technical \\ Univercity of Oil and Gas \\ Ivano-Frankivsk, Ukraine \\ orlovav@ukr.net; \\ https://orcid.org/0000-0003-3882-9191
}

\author{
Sofiia Kafka* \\ Accountig and taxation dept. \\ Ivano-Frankivsk National Technical \\ Univercity of Oil and Gas \\ Ivano-Frankivsk, Ukraine \\ kafka@i.ua; \\ https://orcid.org/0000-0002-6031-383X \\ Orest Boichuk \\ International Relations dept. \\ Vasyl Stefanyk Precarpathian National \\ University \\ Ivano-Frankivsk, Ukraine \\ orest.boichuk@gmail.com \\ https://orcid.org/0000-0002-0433-365X
}

\author{
Iryna Hryniuk \\ Accountig and taxation dept. \\ Ivano-Frankivsk National Technical \\ University of Oil and Gas \\ Ivano-Frankivsk, Ukraine \\ ira.hryniuk@gmail.com \\ https://orcid.org/0000-0002-5739-1159
}

\begin{abstract}
In market conditions, competition is the main mechanism for regulating economic relations. It poses the problem of ensuring the survival and the possibility of further development of enterprises, which requires the participants of the economic process to take adequate measures to improve the mechanism, forms and methods of management. In these circumstances, it is especially relevant to study the issues of formation, operation, reproduction and management of capital of enterprises, and especially its working part. Working capital is a compulsory element of production that provides all the current activities of business entities.
\end{abstract}

The article deals with the etymology and concept of capital, as well as its component - current capital. It is proved that in order to increase the efficiency of the process of managing the current capital of the enterprise, it is important to find the optimal ratio of its components. In such circumstances, the process of optimization becomes a feature of the current capital management strategy. It is established that the most relevant to the optimization process will be a moderate strategy of system-oriented current capital management. On this basis, optimization covers the study of patterns and relationships between all components of current capital. In order to study these relationships, it is necessary to determine the impact on each component of the rest of the current capital components. These relationships are cyclical, and we find that their descriptions are appropriate using mathematical models. Accordingly, models for optimizing the size of the basic elements of current capital using the Lotka-Volterra equation have been developed.

It has been proved that such model allows to estimate the level of mutual influence between components of current capital and to carry out the analysis with the purpose of making effective management decisions. In addition, in order to obtain adequate data on the behaviour of current capital components, it is appropriate in the future to determine the factors influencing them and the magnitude of the weighting factors that will correspond to them. These coefficients were determined using the method of expert estimation using the technique of point estimation.

It has been established that the determination of the maximum and minimum levels of values for the components of current capital has a significant impact on the process of system-oriented management, and the factors that influence these levels will be represented by the indicators that are characterized by the following parameters. In the simulation process it has been found that the most important element, on which the managers of the enterprise in the decision-making process regarding current capital should focus, is the value of stocks taking into account their maximum allowable level.

The theoretical and methodological significance of the study is to substantiate and evaluate the strategy of optimizing the size of the basic elements of current capital, which will allow to set the size of the components of current capital at the optimum level, ensuring the continuity of economic activity, and will also allow to assess the future risks associated with current capital.

Keywords - current capital, current capital's components, optimization, current capital management

\section{I.INTRODUCTION}

The problem of current capital at the current stage of development of the Ukrainian economy is very urgent and will remain so in the future. It is important for the activity of each enterprise, because there is no enterprise without current capital.

Current capital is a generalized category, which includes three components, and requires a systematic approach to the process of mathematical modelling taking into account the interactions between its components.

In the process of the current capital management the optimization of the structure and size of its components are very important. To optimize the value of the current capital 
the primary task of management personnel is to choose the appropriate policy for managing stocks, money and receivables. In order to ensure the optimal value of the current capital it is necessary to develop effective mechanisms for managing each component of the current capital. The development of such mechanisms is possible with a deep and detailed analysis of the impact of each factor on each component of the current capital. Particular attention needs to be given to adapting the external factors: reorientation to the new markets, improving the competitiveness of products, lowering their value and improving quality, re-equipment of the workplaces according to the environmental conditions, adapting to the changes in current legislation.

\section{II.CONCEPTUAL FRAMEWORK AND LITERATURE REVIEW}

The term "capital" comes from the Latin "capitalis" - "of the head" in sense "head of cattle" [1], what means the main. The concept of "the current capital" emerged in the XVII century with signs of primitive accumulation of wealth with signs of primitive accumulation of wealth. The first owners of the capital were the merchants who had acquired the property through the exchange of goods. The main capital (assets) included ships and vans with horses, through which the merchants transported the goods, and the current (working) capital purchased goods for further resale. This is how the concept of the current capital came into being. This term was first used in Germany and France and meant a major asset or principal.

During the historical development and evolution of society approaches to defining the essence of the concept of "capital" have been constantly changing in accordance with the scientific knowledge in each historical epoch. In the process of studying the economic literature, there are many approaches to the recognition of the concept of "capital".

The term of the current capital is a political economy category. Capital is one of the main factors of production, along with the land and the labour of the people. Historically, understanding of the capital has been equated with understanding the wealth of a nation. François Kene, head of the School of Physiocrats, formed the foundations of the theory of social capital's reproduction. F. Kene developed the first macroeconomic model based on the movement of the aggregate social product between the productive and unproductive classes of citizens. Representatives of the school of physiocracy were the first to transfer the study of economic phenomena from the sphere of circulation into the sphere of production, thereby making the first step to the understanding of capital as a category of the sphere of production. They divided all capital into primary, namely fixed capital and annual advances, namely the working capital.

The Scottish economist A. Smith made a significant contribution to the development of the theory of capital circulation. He argued that the capital can be both in the form of funds and in the form of tangible assets, however, real embodiment is essential. Forming the definition of capital A. Smith first of all drew attention to the stocks: "Stocks are divided into two parts. That part of the stocks from which is expected to earn a profit is called equity. The other part is that which goes to direct consumption" [2]. A. Smith divided capital into fixed and working and introduces them into political economy. He formed the assertion that capital characterizes the produced production: workers acquired abilities to work.

To the fixed capital he included as already familiar concepts tools and labour, and a new category "human capital", under which he understood the capitalized value of "acquired and useful abilities of all residents and members of society" [2]. A. Smith formed the proposition that capital characterizes the means of produced production: the workers' acquired abilities to work. He stressed that fixed capital is profitable without leaving its owner. According to the A. Smith's regulation, the working (current) capital consists of goods that bring profit to their owners if they are sold during the production cycle. English economist D. Ricardo, being both a follower and opponent of A. Smith, understood under the working capital some money spent in the production process and argued that the decisive feature of fixed capital is its durability, strength, slow wear. D. Ricardo also divided the capital into the fixed and working capital. On his view, capital can be attributed to the fixed or working based on the speed of its wear and the frequency of its need for reproduction.

Its main contribution to political economy was the allocation, as a criterion of the division of the capital, the time of circulation (reproduction) [3].

Stocks, trade accounts receivable (hereinafter receivables) and money, including their equivalents and current financial investments (hereinafter money) are those assets that provide the basic processes in the enterprise (production, sales, payments), which confirms the importance of managing it effectively.

So, the current capital is a totality of material assets and cash flows, both in their direct form and in the form of investments, which are in constant circulation in order to ensure the continuity of the production process and liquidity of the enterprise, changing its material form during one operating cycle [4].

\section{III.THE AIM AND OBJECTIVES OF THE ARTICLE}

\section{A. The aim of the article}

The aim of the study is to improve the methodological tools for effective operational management of working capital of enterprises.

\section{B. Achieving this goal required completing the following} tasks:

1. To reveal the organizational and economic essence of capital and its components, features and methods of evaluating the efficiency of the working capital of the enterprise.

2. To suggest approaches and methods for finding the optimal ratio of working capital components.

3. To develop models of optimization of the size of the basic elements of working capital by means of the Lotka-Volterra equation.

4. To develop and substantiate the feasibility of evaluating the strategy of optimizing the size of the basic elements of working capital, which will allow 
to set the size of the components of working capital at the optimum level.

5. Identify and experimentally verify the basic conditions for obtaining adequate data on the behavior of the components of working capital.

\section{IV.RESEARCH RESULTS}

All current capital components are interconnected, and they are the parts of the production process, which is not possible in the absence of one of them.

Thus, the purpose of the current capital management is to provide the enterprise with enough of money to settle its short-term liabilities and to ensure a further production process. Formation of the current capital management system is aimed at solving several tasks, determining the relationships between the components of the system, the risks of cash shortages and inventory damage, the choice of methods and means of achieving the set goals.

The essence of the current capital management consists in determination of effective forms and sources of its financing, optimize the volume and structure of its components, ensure the level of liquidity adopted by the enterprise and increase their efficiency. A major feature of the current capital is the significant changes in time. The current capital is managed by the managing of each component of its.

The team of authors, edited by N. Vlasova [5], argues that the optimization of current capital components is an "objective necessity" and "a priority direction". The economic dictionary edited by J. Zavadskyy defines the optimization as "the process of finding such system state, which provides the maximum or minimum of the values of some functions of the system (the choice of the best option from many possible" [6].

Questions related to the development of models and mechanisms of the current capital management are considered in the works of large numbers of economists. In particular S. Kuznetsova and I. Iricov [7] propose a mathematical model of the current capital movement as a dynamic change in cash flows and reserves of current assets, describing it as a classic Marx theory of 'Capital - Goods Capital', scilicet in the form of a transformation from one form to another by the cyclic way. This model is simple and does not take into account all interconnections with assets that have an impact on current capital. T. Chupilko and S. Chupilko [8] offers a dynamical economics-mathematical model for optimization the enterprise's income in the conditions of limited current capital, taking into account time-varying parameters, using numerical methods of simulation modelling. The model proposed by authors is multifactorial, its mathematical description is rather complex and cumbersome, thus it is difficult for using and understanding. I. Shyndyruk [9] in order to solve financial problems proposes to use an economic-mathematical model of finding the optimal set and ratio of sources and methods of financing the enterprise, by the mathematical formulation of the problem of optimization of capital structure by the criterion of its lowest value, which based on the minimization of the role of its target function. This model is based on the number of already developed and calculated indicators, which by their nature are subjective, and the results of this model cannot be considered reliable.

Important for the formation of an effective system of the current capital management is the process of the optimization the structure of its components. The optimization process is based on the relationships and interactions between the components of the current capital. The mathematical model of the optimization of the current capital components consists in determination of optimum value of each component, which will enable the enterprise to use more efficiently the available resources and the production capacities and to prevent the irrational waste and investment of resources.

Current capital management through the optimization involves explore of the patterns and relationships between all components of current capital.

To explore these relationships, it is necessary to study the effect of each component on the remaining components. These effects can be described as follows:

- The stocks available at the enterprise are formed through the purpose of conducting business activities. Their size should be sufficient for the normal production process and not create excess reserves that will be subject to ageing and deterioration. At the same time, the company's ability to provide the required level of stocks decreases with a continuous increase in outstanding receivables and increases in cash that does not have a direct purpose for their expenses.

- The amount of the receivables arising in the course of doing business determines the size of the operating income of the enterprise and depends on the financial discipline of the enterprise, the amount of money on a specific date, which should ensure the repayment of the current liabilities and the number of shares that have been processed and sold in the reporting period, and also should not cause loss of solvency.

- The amount of the money that guarantees the normal level of solvency and current liquidity of the enterprise by providing the company an amount of the money that will help to comply the payment calendar, namely the ability to pay off its obligations, as well as the need for the purchase of raw materials and the amount of overdue receivables decrease.

To determinate the effect of managing to the value of the one indicator on the value of another is expedient to include the effect of the maximum and minimum permissible values of one or more components of the current capital as a multiplier to the indicator being analysed, the differences between the maximum or minimum allowable value and the actual value of the indicator.

A significant impact on the process of the current capital management have maximum and minimum levels of values of its components.

The maximum level of the current capital components impacts on:

- Determination of the maximum allowable level of stocks will help to determine the optimal size of the 
order and the cost of their transportation and maintenance, prevent the emergence in the warehouse of the surplus stocks that can be spoiled and become unfit for their processing.

- Determination of the maximum allowable level of receivables will allow establishing the value of receivables that an enterprise can account on the balance sheet without losses of solvency and violation of normal financial discipline.

- Determination of the maximum allowable level of money will allow to optimize the amount of cash flows and makes decisions about investments.

The minimum level of the current capital components impacts on:

- Determination of the minimum allowable level of stocks will ensure the continuity of the production process, prevent production failures in the emergencies, determining the optimal size of the order and the costs of their transportation and maintenance.

- Determination of the minimum allowable level of receivables will characterize the minimum necessary in operation income, which will provide the level of profit necessary for normal business activities.

- Determination of the minimum allowable level of money will determine the basic principles of the credit policy of the enterprise, facilitate the implementation of the company's financial obligations and determine the enterprise's possibility of financial investment.

Exceeding the maximum amount of cash and receivables required by the enterprise enables the company to make decisions related to financial and investment activities and earn additional profits. It is important to emphasize that the maximum allowable levels of receivables and cash are not absolute figures. The maximum allowable levels of receivables and cash are not absolute indicators. They characterize the amount that enables an enterprise to conduct operations and counter the threats that are associated with it. However, this does not mean that its exceeding will be negative for the enterprise. On the contrary, such an excess would have a positive impact on the enterprise: it will allow for expansion and development of the enterprise. At the same time, their minimum level is a relatively absolute indicator, which characterizes the minimum below which an enterprise cannot afford to conduct business activities, keeping the basic indicators at a minimum level without significant losses and threats. The situation is somewhat different regarding stocks. The minimum level of stocks characterizes the amount required by the enterprise to prevent downtime in production and the formation of minimum indicators of receivables and cash. However, their maximum level is not an absolute relative value. It shows the amount of stocks that can be consumed and sold by the enterprise, given the economic conditions and production capacity, and the amount of stocks that exceeds the maximum level which may create inconvenience associated with its storage, as well as be subject to ageing. Consequently, they will be an irrational cost to the enterprise.
The optimization process should be based on the main goal set by the company's management personnel regard to the current capital components. The optimization process is not about determining the minimum or maximum size of the components of the current capital that can afford to keep an enterprise without creating a threat to business. Its main purpose is to identify the relationships and interactions between the components of the current capital and to establish such a value of each of the components that will contribute to ensuring the continuity of the enterprise's business activities at a minimum level of costs associated with their formation and maintenance, as well as associated with freezing capital in these components, that is, maneuverings separately for each component of current capital in the general management system. The essence of the optimization process will be to formulate such an adaptive mathematical model that could satisfy the needs of the enterprise managers in informing the process of managing the components of the current capital by setting such sizes of its components that will guarantee maximization of profit while minimizing costs, namely setting such parameters that will not efficiency of direct production of products, but also formation of the enterprise value and its image on the market in.

A mathematical model is a description of a system using mathematical concepts and language. The process of developing a mathematical model is termed mathematical model-making [10].

The most widely used in various fields of science and technology, including economics, is the model independently formed by Alfred James in 1925 and Vito Volterra in 1926, the so-called Lotka-Volterra equations or the predator-prey equations. This model is a system of two a pair of first-order nonlinear differential equations, frequently used to describe the dynamics of biological systems in which two species interact, one as a predator and the other as prey [11]. The solution of this system is auto-oscillation. With the help of this system is possible to carry out a comprehensive assessment of the economic processes' dynamics and to forecast their behaviour in the future, subject to changing model parameters.

The relationships which were described above can be represented by the Lotka-Volterra equation as follows:

$$
\left\{\begin{array}{l}
x^{\prime}(t)=k_{1} x(t)-k_{2} y(t)+k_{3} z(t) \\
y^{\prime}(t)=k_{4} y(t)+k_{5} x(t)+k_{6} z(t) \\
z^{\prime}(t)=k_{7} z(t)-k_{8} x(t)-k_{9} y(t)
\end{array}\right.
$$

where,

$x^{\prime}(t), y^{\prime}(t), z^{\prime}(t)$ is the need of stocks, accounts receivable and cash for the period;

$x, y, z$ is the amount of stocks, accounts receivable and cash respectively;

$k_{1}-k_{9}$ is the significance coefficients of the factors influence on the value of the indicator.

This model gives an opportunity to assess the level of interaction between the current capital components and provide the analysis to make effective management decisions. 
It should be noted that this model is general-based and can be modified in accordance with the needs of an enterprise, its conditions of manufacturing or the object of management. In order to determine the effect of managing the value of one indicator on the value of another is expedient in this model to include the effect of the maximum and minimum permissible values of one or more components of current capital as a multiplier to the indicator being analyzed, the differences between the maximum or minimum allowable value and the actual value of the indicator.

In order to obtain adequate data on the behaviour of current capital components in the future is advisable to determinate the affecting factors on them and the amount of the coefficients that they will be responsible for. Determination of these coefficients is carried out by means of expert estimations using the technique of ball assessments. Expert estimation methods are a way of forecasting and evaluating future results based on expert forecasts. The technique of ball assessments consists in the expert assessment of certain parameters in points or their distribution according to certain criteria, with subsequent assignment of points in the processing of data. The method of questioning was used to collect information on experts' assessment of the affecting factors. Respondents interviewed using the Google Forms product on the Google platform by sending a questionnaire to respondents' email addresses. To determine the amount of the importance of the affecting factors on the current capital components, is suggested using a scale from 0.1 to 0.9 , where 0.1 represents the lowest level of influence, and 0.9 is the highest level. Also, experts are asked to determine the parameter (stocks, accounts receivable, cash) by the method of ranking to the equation of which this factor has the highest impact.

The estimation of the importance level of the affecting factors to the current capital components (coefficients $k_{1}-k_{9}$ ) was carried out in several stages with a series of indicators of consistency. The value of the coefficients determined by the expert estimation method are:

- $\quad$ Planning a delivery schedule $\left(k_{1}=0.4\right)$

- Increase in the maturity terms of accounts receivable $\left(k_{2}=0.2\right)$.

- Accumulation of a significant amount of cash without making investment decisions $\left(k_{3}=0.4\right)$.

- Ratio of outstanding receivables $\left(k_{4}=0.4\right)$.

- $\quad$ Compliance the production schedule $\left(k_{5}=0.1\right)$.

- Planning a billing calendar $\left(k_{6}=0.2\right)$.

- $\quad$ Effective financial discipline $\left(k_{7}=0.25\right)$.

- The accuracy of determining the optimal order size $\left(k_{8}=0.3\right)$.

- Growth in the number of outstanding receivables $\left(k_{9}\right.$ $=0.15$ ).

The factors influencing the maximum and minimum levels will be the factors that characterize these parameters:

- $(A-x(t))$ is the impact of the maximum allowable level of stocks;
- $(B-y(t))$ is the impact of the maximum allowable level of receivables;

- $(C-z(t))$ is the impact of the maximum allowable level of cash;

- $(x(t)-D)$ is the impact of the minimum allowable level of stocks;

- $(y(t)-E)$ is the impact of the minimum allowable level of receivables;

- $\quad(z(t)-F)$ is the impact of the minimum allowable level of cash.

According to this condition, the parameters $A, B, C, D, E$, $F$ will represent the maximum and minimum levels of stocks, receivables and cash respectively. Hole these factors must be included into the Lotka-Volterra equation.

Through the method of checking options has been the gradual inclusion of factors to choose a strategy that will satisfy the management personnel with their results and will enable the size of the components of current capital at the optimal level, ensuring the continuity of economic activity, and will enable to assess future risks associated with current capital. In the process of optimization, studying the interrelationships and interactions of the current capital components among themselves, during the simulation, it was established that the indicators of the maximum and minimum allowable levels of components do not play a significant role in determining the optimal value of the turnover of cash and receivables. The main for this process will be the principle of continuity the activity. As any activity of the enterprise is oriented to the future and at the present time it is not taken into account the bankruptcy or liquidation of an enterprise in the normal course of business and in the normal production process, according to which the acquisition of stocks, their processing and posting of finished products are the main elements of the activity, and as well as its further realization for profit in the current reporting period. It is from the processes of ordering and selling will depend on the size of cash flows of the enterprise, as well as the number of receivables. In the process of simulation, it has been established that the most significant element in which the managers of the enterprise should be focused in the process of making decisions on current capital. It is the magnitude of stocks, considering their maximum permissible level. By analysing the graphics data obtained during the research the following basic model of optimization of current capital components has been formed:

$$
\left\{\begin{array}{c}
x^{\prime}(t)=k_{1} x(t) \cdot(A-x(t))-k_{2} y(t)+k_{3} z(t) \\
y^{\prime}(t)=k_{4} x(t)+k_{5} y(t)+k_{6} z(t) \\
z^{\prime}(t)=k_{7} z(t)+k_{8} x(t)-k_{9} y(t)
\end{array}\right.
$$

Entering the initial data of enterprises in this model: the average value of annual demand in stocks, with the adjustment on their maximum allowable level, receivables and cash received graphs of the behaviour of current capital components and the predicted values of these components in the perspective of five years.

In the process of modelling, graphs of behaviour of current capital components have been obtained, which make it possible to assess the future performance of an enterprise. 
As can be seen from the established data, the indicators formed with this model correspond to the main criteria. The value of each of these indicators exceeds the minimum required level of each type of asset. Thus, all enterprises can conduct further economic activity, increasing their profitability and liquidity. Also, these figures are within the set maximum permissible levels that may allow the holding of the enterprise. Talking about stocks, their projected volume is close enough to the maximum allowable level. It is the maximum allowable level that determines the need for an enterprise in all types of stocks within one year with the formation of their reserves, which will enable them to conduct continuous business activities and be risk resistant. Objective remains the fact that the calculated forecast indicators are not definitive to which the enterprise will come. These indicators enable enterprise personnel to assess all risks, all the benefits of certain investment decisions, concepts, strategies and models adopted in the enterprise, both in terms of current capital and other indicators with which this type of assets is closely related. Application of this model in practice will make it possible to reduce the costs associated with managing the components of current capital, the normalization of these components and the search for various strategies and concepts for their optimization.

All calculations and defined indicators are based on actual indicators of activity of enterprises. Approbation of the above model was conducted based on financial reporting indicators of nine companies in the oil and gas industry.

In the Tab. I. is showed the result of the implementation of model (2) at three Ukrainian full-cycle petroleum enterprises. The implementation means the forecast of current capital components' amount for the next five years.

TABLE I. FORECASTED INDICATORS OF CURRENT CAPITAL COMPONENTS

\begin{tabular}{|c|c|c|c|c|c|c|c|c|c|}
\hline \multirow{2}{*}{$\begin{array}{c}\text { Year } \\
(\text { mil } \\
\text { UAH })\end{array}$} & \multicolumn{3}{|c|}{ Enterprise 1 } & \multicolumn{3}{c|}{ Enterprise 2 } & \multicolumn{3}{c|}{ Enterprise 3 } \\
\cline { 2 - 10 } & Stocks & $\begin{array}{l}\text { Recei- } \\
\text { vables }\end{array}$ & Cash & Stocks & $\begin{array}{l}\text { Recei- } \\
\text { vables }\end{array}$ & Cash & Stocks & $\begin{array}{l}\text { Recei- } \\
\text { vables }\end{array}$ & Cash \\
\hline 1 & 1869 & 35390 & 12770 & 23310 & 49010 & 63690 & 961,2 & 5337 & 6995 \\
\hline 2 & 1869 & 42740 & 14250 & 23310 & 81070 & 101900 & 961,2 & 8126 & 10640 \\
\hline 3 & 1869 & 51130 & 15170 & 23310 & 126200 & 157500 & 961,2 & 12140 & 15990 \\
\hline 4 & 1869 & 60490 & 14960 & 23310 & 190300 & 238800 & 961,2 & 17950 & 23890 \\
\hline 5 & 1869 & 70600 & 12730 & 23310 & 281800 & 358100 & 961,2 & 26390 & 35570 \\
\hline
\end{tabular}

As we can see from the calculated data is clear that two enterprises will face the problem of the timely repayment of receivables by counterparties. This is evidenced by a significant excess of the amount of receivables over the amount of cash. Among these Enterprise 1 and Enterprise 3. For Enterprise 2 the value of incoming cash flow is higher than the value of receivables, indicating that effective investment and more profit timely repayment contractors and collect old debts. However, the incoming cash flows are significantly lower than the current accounts receivable. Further, providing of economic activity on such conditions will threaten enterprises with significant loss of liquidity, solvency and possible bankruptcy.

\section{V.CONCLUSIONS}

Conduction the analysis of the calculated data, we see that if the enterprises comply with today's methods of management and credit policy, as well as the absence of any changes in them for several enterprises, there may be problems with solvency. Since the magnitude of the projected reserves is optimal and satisfies the needs of all enterprises meeting the conditions of production capacity, this aspect does not require additional adjustments. The two most problematic areas are: accounts receivable and cash. Accounts receivable, being the result of the sale of stocks, in the reporting period should objectively exceed the amount of stocks. Contrary to that, according to the classification of the current capital components to stocks included all kinds of raw materials, manufacturing and finished goods, in the process of optimizing considered only the value of consumed raw materials, components and other assets necessary for production. That is the size of optimized stocks is essentially close to the value of production cost of the enterprise's finished product. Thus, accounts receivable over a period should exceed the amount of these stocks, as it is appropriate to implement all manufactured products in the normal course of business. Since selling is carried out on post payment, the value of incoming cash flows is not always equal to the number of current receivables. That this is the main element in the management of the enterprise: monitoring the timely collection of receivables and an enough incoming cash flows to ensure that the minimum needs of the enterprise in cash.

\section{REFERENCES}

[1] Lewin, P., and N. Cachanosky. "Substance and semantics: The question of capital." Journal of Economic Behavior \& Organization 150
https://doi.org/10.1016/j.jebo.2018.01.024.

[2] Smith, A. Research on the nature and causes of the wealth of peoples. Moscow: Eksmo, 2009. [in Russian].

[3] Ricardo, D. The Beginnings of Political Economy and Taxation. Moscow: State Political Publishing House, 1941. [in Russian].

[4] Hryniuk, I. Methodical Approaches to Determining the Essence of Working Capital, in Proceedings of the Second All-Ukrainian Scientific and Practical Internet Conference with International Participation. Lutsk: vol. 3, pp. 156-159, n.d. 2016. [in Ukrainian].

[5] Vlasova, N. Management of Working Capital at Retail Enterprises. Kharkiv: KDUKT, 2014. [in Ukrainian].

[6] Zavadsky, Y., T. Osovskaya, and O. Yushkevich. "Optimization." In Economic Dictionary, pp. 212. Kiyv: Condor, 2006. http://library.nlu.edu.ua/POLN_TEXT/KNIGI/KONDOR/EKONOMI C_SL_2006.pdf [in Ukrainian].

[7] Kuznetsov, S., and I. Irikov. "Mathematical modeling of financial flow management tasks." Electronic Journal Investigated in Russia, 2001, 1442-1464. https://cyberleninka.ru/article/v/matematicheskoemodelirovanie-zadach-upravleniya-finansovymi-okami. [in Russian].

[8] Chupilko, T., and S. Chupilko. "The Mathematical Model for Optimizing the Working Capital of a Trading Enterprise." Collection of Scientific Papers of Dneprodzerzhinsk State Technical University 1, no. 28 (2016), 113-117. [in Ukrainian].

[9] Shindyruk, P. "Economic and Mathematical Modeling and Optimization of the Capital Structure of Enterprises." Finance of Ukraine 2 (2012), 111-118. [in Ukrainian].

[10] Sacco, R., G. Guidoboni, and A. Mauri. "Elements of Mathematical Modeling." A Comprehensive Physically Based Approach to Modeling in Bioengineering and Life Sciences, 2019, 3-17. https://doi.org/10.1016/B978-0-12-812518-2.00009-3.

[11] Yamada, Yoshio. Chapter 6 - Positive Solutions for Lotka-Volterra Systems with Cross-Diffusion. Handbook of Differential Equations. Edited by M. Chipot, 6th ed. North-Holland2008. https://doi.org/10.1016/S1874-5733(08)80023-X. 